Gallagher, S. (in press). On the possibility of naturalizing phenomenology. In D. Zahavi. Oxford Handbook of Contemporary Phenomenology. Oxford: Oxford University Press.

\title{
On the possibility of naturalizing phenomenology
}

\author{
Shaun Gallagher
}

In this chapter I address two questions. First, can phenomenology be naturalized? Second, if so, how? There is some controversy about how to answer the first question, and there are different proposals in response to the second question.

One important clarification about these questions is called for at the very beginning. We should distinguish between two current senses of the term 'phenomenology'. On the one hand, some theorists use the term 'phenomenology' to refer to consciousness itself, specifically the phenomenal aspects of experience, the "what it is like" to experience something. The question of naturalizing phenomenology in this sense (i.e., the question of naturalizing consciousness or the mind, addressed, e.g., by Dretske 1997) often tends to imply a reductionistic project that would ultimately explain consciousness in terms of physical processes. On the other hand, 'phenomenology' also refers to the philosophical tradition originating in Europe with Husserl. In this sense, the question of naturalizing phenomenology would ask about how this philosophical approach relates to natural science, and whether one can employ phenomenological methods in the service of psychology or cognitive science. In this paper I will use the term 'phenomenology', and understand the question, in this second sense. At the same time, responses to the question about naturalizing consciousness and the question about naturalizing phenomenology, in this second sense, are intertwined. On the one hand, if one thinks of philosophical phenomenology as essentially non-reductionistic with respect to consciousness, and of naturalism as always and completely reductionistic in this regard, then naturalizing phenomenology may appear difficult if not impossible. On the other hand, if one thinks that there can be a non-reductionist naturalism, then naturalizing phenomenology may appear a greater possibility.

\section{Can phenomenology be naturalized?}

A natural scientific explanation of consciousness, e.g., a psychological or neuroscientific explanation, accounts for the mind by invoking causality and empirical facts. The transcendental account, in contrast, attempts to say what makes it possible for the mind to be able to invoke something like causality in the first place. Husserl defined phenomenology within this broadly transcendental agenda, with some important differences from the Kantian idea of a transcendental deduction. Specifically, Husserl, in contrast to Kant's hypothetical-deductive method, viewed phenomenology as a way to put ourselves into a transcendental stance or attitude that provides non-empirical access to consciousness as a field of analysis and allows us to see and describe how the mind (or consciousness) is structured.

Husserl was careful about how he defined phenomenology, and he distinguished it from a naturalistic enterprise for two reasons. First, he adopted a traditional concern 
about establishing a firm epistemological foundation for doing science. Like Descartes and Kant before him, he wanted to make sure that the basic categories employed by natural science were not thought to be the products of some merely contingent features of human psychology. Second, he wanted to define the limits of what science, or naturalism broadly construed, can tell us.

Naturalism is a phenomenon consequent upon the discovery of nature ... considered as a unity of spatiotemporal being subject to exact laws of nature. With the gradual realization of this idea in constantly new natural sciences that guarantee strict knowledge regarding many matters, naturalism proceeds to expand more and more.... [T]he natural scientist has the tendency to look upon everything as nature, [just as] the humanistic scientist sees everything as "spirit," as a historical creation. By the same token, both are inclined to falsify the sense of what cannot be seen in their way. Thus the naturalist, to consider him in particular, sees only nature, and primarily physical nature. Whatever is, is either itself physical, belonging to the unified totality of physical nature, or it is in fact psychical, but then merely as a variable dependent on the physical, at best a secondary "parallel accompaniment." Whatever is belongs to psychophysical nature, which is to say that it is univocally determined by rigid laws. (1965, p. 79).

To be clear, Husserl was not opposed to natural scientific explanation. Indeed, he wanted to make sure that science and our knowledge of the laws of nature were firmly grounded. Rather, Husserl was opposed to scientism, the positivistic view that everything is fully explained by natural science. Specifically he regarded the naturalizing of consciousness, including intentionality, but also the naturalizing of norms, and things like formal logic, mathematics, and ideal essences as wrong-headed. In his arguments against psychologism, in the Logical Investigations, for instance, he shows that this extreme naturalism refutes itself by undermining any formal-logical principle or law of nature by reducing it to mere psycho-physical processes. Simply put, on the extreme version of naturalism, if our brain processes evolve over time (which they certainly do), then the laws of nature may be different in the future than they are now. A law of nature would accordingly be relative to the particular neurological or psychological constitution of the historically-situated knowing subject. This is what Husserl wants to reject.

On Husserl's view, psychology, as a legitimate natural science, is one thing; phenomenology is something else. Psychology treats consciousness as belonging to natural human or animal organisms. In conducting their studies and experiments, however, psychologists already and unavoidably employ consciousness in the very obvious sense that they tend to be conscious when they conduct their studies. In taking natural, third-person perspectives on cognition and behavior, that is, in conducting their specific research, psychologists are not concerned with a basic interrogation into the invariant structures that are constitutive of any consciousness whatsoever.

Consider, for example, the temporal structure of consciousness. According to phenomenology, this is something that permeates all experience, all cognitive processes including perception, memory, imagination, judgment, emotion, etc., as well as all action. Although psychological science has long studied reaction times, timing in neuronal 
processing, the subjective experience of time passing, and phenomena such as time estimation, all such studies employ the notion of objective time and attempt to measure these phenomena, literally, by the clock. Even in studies of working memory, researchers raise questions that can only be answered in terms of objective time - how many units of information, or how much representational content can be held in consciousness for how long? Such questions define the nature of the psychological and neuroscientific investigation of such phenomena. Neither psychology nor neuroscience, however, asks about the temporal nature of experience as experienced. The phenomenological question is something like this: what must consciousness be like if the subject is able to experience the passage of time, to remember what just happened, and anticipate what is just about to happen, and perceive temporal objects such as melodies, sentences, horse races, or indeed, any object that endures or changes - including the various instruments used in psychological or neuroscientific experiments to measure time. This question marks the subject matter of Husserl's phenomenological analysis of time-consciousness in terms of a retentional/primal impressional/protentional structure. Without explicating the details of such an analysis here, one could suggest that psychology itself, from the time of William James' (1890) analysis of the specious present through recent attempts to study the neural correlates of temporal experience (e.g., Pöppel 1994), consistently misses the phenomenon of temporality in this sense of a temporal structure that characterizes experience at its most basic level. This is not meant as a criticism of psychology; rather, it is an attempt to point out that psychology, and naturalism more generally, do not aim at this kind of analysis, and do not take the transcendental attitude required for this analysis.

In one sense the transcendental investigation seems more basic; in another sense one might think that the neuroscientific investigation is equally basic. One could put the neuroscientific question in this way: how must the brain function if it allows consciousness to have this retentional/primal impressional/protentional structure? The issue, however, is not about which type of investigation is more basic. It's rather that these are two different kinds of investigations that are not reducible to one another. Accordingly, phenomenologists maintain a strong distinction between phenomenology as a transcendental study, and psychology or neuroscience as a natural science. Precisely for these reasons, some phenomenologists argue that to naturalize phenomenology would be to do something other than phenomenology, or that even to speak of a naturalized phenomenology is absurd (e.g., Lawlor 2009). Phenomenology is defined as a transcendental discipline, conducted within a transcendental attitude. If one takes the naturalistic attitude, then one is not doing phenomenology. If one ignores Husserl's antinaturalism and proposes to do phenomenology within the natural attitude, then that just isn't phenomenology.

\section{A broader conception of phenomenology}

One response to this strict or narrow definition of phenomenology is to point out that phenomenological philosophy involves more than the pure description involved in the transcendental project. Viewing phenomenology in this broader way does not, however, "contradict Husserl's entire conception of phenomenology" (Lawlor 2009, 2). Indeed, Husserl (1977) suggested the possibility of developing a phenomenological 
psychology. This project would differ from transcendental phenomenology but would still be a reflective investigation of intentional consciousness from the first-person perspective, while remaining within the natural attitude. The task of phenomenological psychology is to study consciousness, not as the transcendental foundation of the sciences and the condition of possibility for all meaning, but as a phenomenon in its own right. The idea that one can do phenomenology, or we might say use phenomenology while remaining in the natural attitude signals a way of thinking of phenomenology that is quite different from Husserl's original project which required phenomenologicaltranscendental reductions to escape the natural attitude. But such an approach is clearly consistent with a broader conception of phenomenology held by Husserl himself. Husserl certainly thought that the results of transcendental phenomenology should not be ignored by science, and the idea that they might inform the natural sciences is not inconsistent with the value of transcendental analysis. He suggested, quite clearly, that "every analysis or theory of transcendental phenomenology -including . . . the theory of the transcendental constitution of an objective world - can be developed in the natural realm, by giving up the transcendental attitude" (1970, p. §57).

Lawlor nonetheless worries that the naturalization project "aims to swallow phenomenology up" $(2009,2)$. This rather dramatic way of putting it indicates a point carefully made by De Preester (2002), namely, that given the assumptions of cognitive science concerning issues like computationalism and representation, it seems that there is a basic opposition between phenomenology and cognitive science. Accordingly, if naturalization means that phenomenology simply adopts such assumptions, then phenomenology self-destructs. "A naturalized phenomenology is no longer phenomenology" (p. De Preester 2002, 645). This would be the case, however, only if the question were precisely the one that Edelman (2002, 125) asks: "Is a new phenomenology, which would completely eschew transcendentalism in favor of computational principles, possible?" The issue really goes the other way, however, as De Preester herself notes. That is, the introduction of phenomenology into cognitive science has critically challenged the basic assumptions of cognitive science, including computationalism, and indeed the very concepts of nature and naturalism, and has moved cognitive science towards a view that is more consistent with the views of Husserl and Merleau-Ponty on intentionality, intersubjectvity, action, and embodiment (see Gallagher and Varela 2003; Thompson 2007; Varela, Thompson and Rosch 1991).

Beyond Husserl, others in the phenomenological tradition followed this same path, carrying phenomenology to broader application, and integrating the natural sciences of consciousness and behavior into their considerations. Gurwitsch, Sartre and MerleauPonty, for example, are philosophers who pursue what could be generally called phenomenological psychology. Gurwitsch appeals to Gestalt psychology, animal studies, and developmental psychology to support the proper phenomenological characterization of various experiences. For example, if we want to provide a phenomenological description of how we go about solving a problem in the real world, or how, in that context, a certain object can take on the meaning of a tool, we can benefit from something that Gestalt theorists have described very well: a perceptual reorganization involving the "restructuring of the given situation, the regrouping of the facts of which it is composed" (Gurwitsch 2009, 246). It is only by attending to such reorganizations and reformations of structures that proper phenomenological accounts of such experiences 
can be developed. Gurwitsch further finds evidence in developmental studies that our primary perception of the world is an enactive and pragmatic one where things have their meaning in terms of how we can use them $(2009,250)$. Accordingly, a proper phenomenology of perception needs to take into consideration this full pragmatic meaning of perceptual experience.

In his phenomenological examination of the imagination Sartre draws from empirical psychology. He refers us to Flach's experiments on images associated with presented words, and he offers a reinterpretation of Flach's experiments to work out distinctions between symbols and images (e.g., 2004, 107ff). He considers the views of Binet and the Würzburg psychologists on the relation of image and thought, suggesting, in contrast to Binet, that the image has a sense and may play a role in thought $(2004$, p. 108). In Being and Nothingness, too, Sartre makes use of naturalistic psychological studies to inform his phenomenology.

Merleau-Ponty is well known for his integration of phenomenology, psychology, and neurology. In Phenomenology of Perception, for example, he makes extensive use of the experimental literature and case studies. In lecture courses at the Sorbonne in 195052 (under the title "Human Sciences and Phenomenology") he discusses a "convergence" of phenomenology and psychology, explicating various misunderstandings on both sides of this relationship (2010, p. 317). He takes Sartre's analysis of imagination as a good example of how phenomenological (eidetic) analysis can be integrated with psychology, and shows how eidetic (imaginative) variation works in a correlative way with scientific inductive procedures. Like Gurwitsch and Sartre, Merleau-Ponty appeals to psychology (Goldstein's distinction between centered and decentered behavior, and Koffka's Gestalt psychology) as a possible guide for phenomenological insight, suggesting that "the distinction between phenomenology and psychology must not be presented as a rigid distinction" $(2010,329)$ - without, of course, denying the distinction. Indeed, we can find in psychology itself (specifically in Koffka's distinction between geographical and behavioral environments) a useful way, not only to think of the difference between thirdperson naturalistic accounts, and first-person phenomenological accounts, but to understand why a full third-person (geographical) account (an account as if from nowhere) is impossible.

Following Gurwitsch, Merleau-Ponty rejects the constancy hypothesis (the idea that there is a point-to-point correspondence between stimulus and perception), not by offering an independent phenomenological analysis, but by citing experimental work within psychology itself (see 2010, p. 347). Merleau-Ponty's conclusion is consistent, not only with earlier phenomenological distinctions in Heidegger between Zuhandenheit and Vorhandenheit, but also with more recent naturalistic distinctions, between pragmatic and semantic functions of perception (Jeannerod 1997). Accordingly, these distinctions are correlatively phenomenological and psychological, and they provide supporting evidence for enactive accounts of perception that draw from both phenomenology and natural science.

What we see in each of these cases is, to use Merleau-Ponty's term, a convergence of phenomenology and the natural sciences of psychology and/or neuroscience. This is more than a convergence of results. That is, the convergence is not simply that phenomenology and psychology have reached the same conclusions about specific topics. Indeed, in some cases, there is a critical distance between the view defended by 
phenomenology and the received view of psychological science. Rather, the convergence pertains to how phenomenology is put to use in the research fields of psychology and neuroscience. It's a convergence on a methodological plane. Moreover, the convergence does not signify a change in the definition of phenomenology. Nor is it a threat to transcendental phenomenology. The transcendental project remains as its own phenomenological project. What we find in Husserl's concept of a phenomenological psychology, however, and in the work of Gurwitsch, Sartre, and Merleau-Ponty, is a certain pragmatic application of phenomenological method. Accordingly, these theorists have already provided a positive response to the question of whether phenomenology can be naturalized.

\section{How can phenomenology be naturalized?}

Turning now to the second question, addressing precisely how phenomenology can be naturalized, several answers have already been proposed in the recent literature. In this regard I will briefly summarize three general proposals without providing anything close to the full critical discussion that each one deserves. I'll then turn to a more extended discussion of specific examples of where phenomenology has been playing a role in natural science accounts of the mind.

\section{Formalizing phenomenology}

One approach to naturalizing phenomenology, proposed by Roy et al. (1999), involves translating the results of phenomenological analysis into a formal language that is clearly understood by science, namely, mathematics. We could call this the CREA proposal, since it was proposed by an interdisciplinary group of researchers at the Centre de Recherche en Epistémologie Appliquée (CREA) in Paris -- Jean Petitot (a mathematician), Jean-Michel Roy (a philosopher), Bernard Pachoud (a psychiatrist), and the late Francisco Varela (a neurobiologist). They write, "It is our general contention ... that phenomenological descriptions of any kind can only be naturalized, in the sense of being integrated into the general framework of natural sciences, if they can be mathematized. We see mathematization as a key instrument for naturalization ..." (Roy et al. 1999, 42).

We can understand this proposal as building on the work of Eduard Marbach (1993) who suggested a formal symbolic language for phenomenology. One important question is whether it is possible for mathematics to capture the lived experience described by phenomenology. The description of lived experience, of course, already involves expressing the experience in language. It takes an additional step to formalize those verbal or written descriptions. This is a strategy that can be employed to clarify word meaning and to facilitate scientific communication. As Marbach $(1993 ; 2010)$ suggests, formalizing the language can improve the possibility of formulating intersubjectively shareable meanings. As in science, terminological problems are addressed through the use of formalized language systems like those found in mathematics. Marbach thus attempts to develop a formalized notation to express phenomenological findings, not just about the content of experience, but about it's structure.

Husserl's analysis of episodic memory, for example, suggested that it involves the 
re-enactment of previous perceptions. He relies on the notion of 're-presentation' (Vergegenwärtigung); literally, 'to make something present again'. Whereas perception is an intentional reference to something present, and thus an activity of 'presentation', memory refers to something absent. Even intentional reference to something absent, however, requires a presentational activity where reference to that which is not present is made "as if" it were given to me in perception (Marbach 1993, p. 61). The "as if" is the re-presentational modification. Marbach, following Husserl's own proposals for formal notation $^{1}$, attempts to make the structure of re-presentation clearer. Let '(PER)x' signify the act of perceiving some object, $x$. Remembering $x$ involves (PER)x, not as an actual and occurent act of perception, but as a reenactment of a past perception. To signify this in the notation, the parentheses become brackets: [PER]x. Furthermore, an element of belief (signified by $* *$ ) distinguishes a reenactment in memory from an imaginary enactment. In other words, in contrast to imagination, episodic memory involves a belief that in the past I actually did perceive $x$. Let ' $p$ ' signify that the perception of $x$ is in the past rather than in the future (to differentiate it from expectation). Marbach thus attempts to capture the structure of an act of episodic memory in the following formulation: '(REP

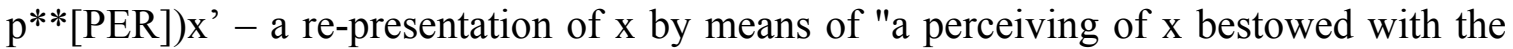
belief of it having actually occurred in the past."

Things get more complicated (see Marbach 2010), but the virtue of formulating a notation like this should be clear if it can show clearly the complexity of consciousness and the explication of that complexity provided by phenomenological reflection. In addition, with respect to these phenomenological insights concerning episodic memory, for example, a formal notation may also help to link up in a precise way with certain neuroscientific findings that indicate memory processes occurring in "the same early sensory cortices where the firing patterns corresponding to perceptual representations once occurred" (Damasio 1994, 101). One could imagine a neuroscientific notation for just such processes correlating with the phenomenological notation for episodic memory. Such notational correlations could make very clear just where phenomenological analysis confirms and supports the neuroscientific model of memory (and reciprocally, where the neurological evidence supports the phenomenological description ${ }^{2}$ ), or precisely where there are differences.

The hypothesis that at some suitable level of abstraction, the phenomenological and the neurological notations would turn out to be consistent, leads directly to the CREA proposal made by Roy et al (1999). ${ }^{3}$ Mathematics is purportedly a formal and therefore neutral language with which we can set out results that are either first-person (the results of phenomenological reflections) or third-person (the results of natural science).

\footnotetext{
${ }^{1}$ See Husserl 2001, $5^{\text {th }}$ Investigation, $\$ 39$, and Husserl 2005, Text No.14 (1911-1912): 363-377; Marbach 2010; Yoshimi 2007. Marbach 2010 also notes the connection with Frege's Begriffsschrift.

${ }^{2}$ Further support for the Husserlian view that memory involves the reenactment of a previous perceptual experience is to be found in neurological differences involved in illusory versus veridical memory. See Schacter, et al. (2006).

${ }^{3}$ We note that Husserl, himself a trained mathematician, viewed mathematical formula as incapable of capturing phenomenological results. "One cannot define in philosophy as in mathematics; any imitation of mathematical procedure in this respect is not only unfruitful but wrong, and has most injurious consequences" (Husserl 1976, 9). Roy et al. argue, however, that even if this was true of the mathematics of Husserl's time, the development of dynamic systems theory offers new possibilities in this regard (1999, p. 43). For some critical remarks see Zahavi (2004).
} 
Specifically, the CREA proposal suggests that a sufficiently complex mathematics, specifically the mathematics of dynamic systems, can facilitate the translation of data from phenomenological and naturalistic realms. In Varela's (1996) specific proposal for a neurophenomenology we can see a good example of how phenomenology, experimental brain science and dynamical systems theory can be integrated in a way that pushes cognitive science in a new direction. ${ }^{4}$

\section{Neurophenomenology}

The aim of neurophenomenology is to incorporate phenomenological investigations of experience into neuroscientific research on consciousness. Neurophenomenology focuses especially on the temporal dynamics of conscious experience and brain activity (Lutz 2002; Lutz and Thompson 2003; Thompson, Lutz, and Cosmelli 2005). Varela formulates the "working hypothesis" of neurophenomenology in the following way: "Phenomenological accounts of the structure of experience and their counterparts in cognitive science relate to each other through reciprocal constraints" (1996, p. 343). By "reciprocal constraints" he means that phenomenological analyses can help guide and shape the scientific investigation of consciousness, and that scientific findings can in turn help guide and shape phenomenological investigations. An important feature of this approach is that dynamic systems theory can mediate between phenomenology and neuroscience. Neurophenomenology thus comprises three main elements (see Figure 1):

(1) Phenomenological accounts of the invariant categorical and structural features of lived experience;

(2) The use of formal dynamical approaches to model these structural invariants; and

(3) Neurophysiological measurements of large-scale, integrative processes in the brain.

Reciprocal constraints means not only (i) that the subject is actively involved in generating and describing specific experiential invariants, and (ii) that the neuroscientist is guided by these first-person data in the analysis and interpretation of physiological data, but also (iii) that such phenomenologically enriched neuroscientific analyses provoke revisions and refinements of the phenomenological accounts, as well as facilitate the subject's becoming aware of previously inaccessible or phenomenally unavailable aspects of his or her mental life. Preliminary examples of this third step can be found in neurophenomenological studies of epilepsy (Le Van Quyen and Petitmengin 2002) and pain (Price, Barrell, and Rainville 2002).

\footnotetext{
${ }^{4}$ Jean Petitot also provides good examples of this approach in his analyses of spatial perception (Petitot 1999; 2008), as does Varela (1999) in his dynamical analysis of time-consciousness.
} 


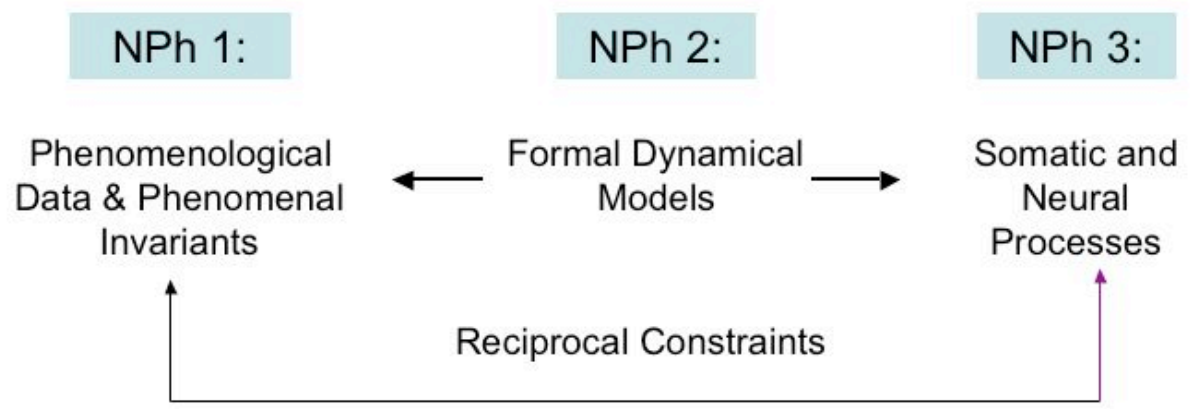

Figure 1: Neurophenomenology (from Thompson 2007).

Neurophenomenology aims to integrate the invarient structures of subjective experience with the real-time characterization of large-scale neural activity. This involves producing phenomenological accounts of real-time subjective experience that are sufficiently precise and complete to be both expressed in formal and predictive dynamical terms, and showing that such experiences are realized in specific neurodynamical properties of brain activity. Accordingly, neurophenomenology takes the framework of dynamic systems theory as important for characterizing the neural processes relevant to consciousness (see Le Van Quyen 2003). Such phenomenological, formal, and neurobiological descriptions of consciousness could provide a robust and predictive way to link reciprocally the experiential and neurophysiological domains.

The practice of neurophenomenology, in the lab, requires training subjects to employ phenomenological methods, including the epoché, and to deliver consistent and clear reports of their experience. Specifically Varela (1996) identified three steps in phenomenological method.

(1) Suspending beliefs or theories about experience (the epoche);

(2) Turning to experience and gaining intimacy with it (phenomenological reduction and focused description);

(3) Developing descriptions and using intersubjective validations (intersubjective corroboration).

In effect, this follows standard phenomenological method in which we bracket opinions, beliefs, and theories about our experience, reflectively turn our attention to that experience to develop a detailed description, and produce a report that can be compared with other reports of the same sort of experience.

Many aspects of experience are not noticed immediately, but require multiple sessions. The repetition of the same task in an experimental setting allows for new contrasts to arise, and can help us to discover consistent categories and structural invariants in experience. The reduction can be either self-induced by subjects familiar with it, or guided by the experimenter through a set of open questions - questions not directed at opinions or theories, but at experience. 
To train the subjects, open questions were asked to try to redirect their attention towards their own immediate mental processes before the recordings were taken. ... For example: Experimenter: 'What did you feel before and after the image appeared?' Subject S1: 'I had a growing sense of expectation, but not for a specific object; however when the figure appeared, I had a feeling of confirmation, no surprise at all'; or subject S4: 'it was as if the image appeared in the periphery of my attention, but then my attention was suddenly swallowed up by the shape'. (Lutz et al. 2001)

In the context of experiments, questions posed immediately after the experimental task help the subjects to redirect their attention towards their experience. Subjects can be reexposed to the stimuli until they find "their own stable experiential invariants" to describe the specific elements of their experiences. These invariants can then become the defining elements that are used as analytic tools in further trials. ${ }^{5}$

\section{Front-loaded phenomenology}

Another closely related approach to integrating phenomenology and experimental cognitive science has been called "front-loaded phenomenology" (Gallagher 2003; Gallagher and Brøsted Sørensen 2006). This approach is closely connected with neurophenomenology in the sense that front-loaded phenomenology can draw on the results of neurophenomenological experiments. At the same time the basic strategy of front-loaded phenomenology is integral to doing neurophenomenology properly. Rather than starting with the empirical results (as one would do in the formal mathematical approach), or with the training of subjects (as one would do in neurophenomenology) this approach starts with the experimental design. The idea is to incorporate phenomenological insights into the design of experiments, that is, to allow the insights developed in phenomenological analyses to inform the way experiments are set up. The phenomenological insights might be drawn from Husserlian transcendental investigations, or from neurophenomenological experiments, or from the more empirically oriented phenomenological analyses found, for example, in Merleau-Ponty (1962). To front-load phenomenology does not mean to presuppose or automatically accept the phenomenological results obtained by others. Rather it involves testing those results and more generally a dialectical movement between previous insights gained in phenomenology and preliminary trials that will specify or extend these insights for purposes of the particular experiment or empirical investigation.

The idea that one can incorporate the insights of phenomenology into experimental protocols without training subjects in the method is not meant as a rejection of the neurophenomenological approach. As already indicated, neurophenomenological experimentation can be an important source of insights for front-loading. Front-loaded phenomenology, however, can address certain limitations involving training in neurophenomenological procedures. Specifically not every psychological experiment can be designed to allow for the training of subjects in phenomenological methods. In some cases one wants the subject to be naïve about what is being tested, for example. In other cases one might be testing subjects who are unable to follow phenomenological

\footnotetext{
${ }^{5}$ For further theoretical and methodological discussion of this experiment, see Lutz (2002).
} 
method (e.g., young children or pathological subjects). In such cases, it may still be possible to employ the front-loading technique.

Experimental design is always based on some concept or distinction. Most often such ideas come from previous experiments. If one traces these ideas back far enough, however, one finds that some of the concepts and distinctions are based on previously operationalized concepts that are themselves drawn from folk psychology, our everyday natural attitude, or varying philosophical traditions. In this regard there may be less control involved in experimental design than the experimenters believe; specific theories lurking in the background may already introduce certain biases that are shaping the kind of conclusions that can be drawn from the experiments. To the extent that the concepts and distinctions incorporated into the experiment are generated in careful phenomenological analyses, closer to experience and less influenced by established theoretical considerations, the scientist gains a certain degree of control that is otherwise missing.

A good example can be found in the much discussed experiments on free will conducted by Benjamin Libet (1985; Libet et al. 1985). In these experiments Libet appealed to philosophical concepts of mental causation and agency that can be traced back to Descartes - namely, the idea that free will is consistent with the conscious control of bodily movement. Haggard and Libet (2001), for example, frame the question in exactly this way, and refer us directly to the traditional question: "how can a mental state (my conscious intention) initiate the neural events in the motor areas of the brain that lead to my body movement?" (p. 47). In more recent experiments Tsakiris, Haggard and colleagues (e.g., Tsakiris and Haggard 2005a\&b; Tsakiris, Prabhu and Haggard 2005; Tsakiris et al. 2007a\&b), as well as others engaged in brain imaging experiments (e.g., Farrer and Frith 2002; Farrer et al. 2003) have adopted a more phenomenologically informed definition of agency - one that takes into consideration the effects that actions have on the environment (see Skewes 2011 for this history of this development). Specifically, they make reference to a phenomenological distinction between the sense of agency and the sense of ownership (Gallagher 2000), which motivates the experimenters to control for the sense of ownership when they want to focus on agency, and vice versa.

\section{Phenomenological interventions in ongoing debates}

To move beyond formal proposals for naturalizing phenomenology and to clarify how phenomenology is already contributing to a number of ongoing debates in the cognitive sciences, it will be helpful to provide a brief overview of several of these research areas.

\section{Embodiment and Agency}

In general the ongoing development of the theory of embodied cognition in the cognitive sciences, has been heavily influence by the resources of phenomenology, with respect to issues in the areas of both artificial intelligence / robotics (Dreyfus 1973) and neuroscience (e.g., Varela, Thompson and Rosch 1991). Recent works continue along this line and draw especially on the work of Merleau-Ponty (e.g, Gallagher 2005; Noë 2004). It would be impossible to summarize the vast array of issues involved in this research area in this short chapter. Accordingly, I will limit discussion here to a small corner of research on embodied cognition and action. The distinction between the sense 
of agency (SA) and sense of ownership (SO) is a good place to start, first, because it is a phenomenological distinction that has found it's way into a significant number of experimental studies (as such, an example of front-loaded phenomenology), and second, because it has been reciprocally productive; that is, it has been productive not only for clarification of the science, but also for phenomenological analysis.

Numerous phenomenologists have indicated that there is a sense of "mineness" or ipseity built into every experience. This is sometimes called the sense of ownership, where ownership means not some external relation of having something (as in ownership of property), but signifies the intrinsic 'ownness' or mineness of experience, an aspect of the experience that makes it subjectively my experience. SO, as such, holds not only with regard to experiences of my body or my body parts, e.g., when I reach and grasp something, the sense that it is my arm that is reaching and my hand that is grasping, but also in regard to my experiences of self-movement and action - this is not only my arm, but also my action. SO also holds with respect to my thinking or stream of consciousness. It is directly tied to the phenomenological idea of pre-reflective selfawareness, i.e., when we consciously think, or perceive, or act, we are pre-reflectively aware that we are doing so, and this pre-reflective awareness is something built into experience itself, part of the concurrent structure of any conscious process.

Pre-reflective self-awareness, however, also involves a sense of agency, which is conceptually distinct from SO: the pre-reflective experience that I am the one who is moving or undergoing an experience. SA can be defined as the pre-reflective experience that I am the one who is causing or generating a movement or action or thought process. This is a phenomenological distinction that can be easily understood in the experience of involuntary movement. If someone pushes me from behind, I experience the initial movement as something happening to me, as something that I am experiencing, and so have an experience of ownership for the movement. I do not claim that it is someone else who is moving, since I have an immediate sense that I am the one moving. At the same time, however, I can say that I have no experience of self-agency for this movement. I did not cause it; someone else pushed me. So in the case of involuntary movement (as well as in reflex movement) SA and SO come apart. In the case of voluntary action, on the other hand, SA and SO seem tightly fitted and indistinguishable in pre-reflective experience.

Neuropsychologists have found this distinction useful for clarifying their studies of agency and perceptual illusions, for example, the rubber hand illusion and whole body displacement. I'll start with the studies of agency. One question experimenters have tried to answer concerns the neural correlates for SA. Let's think again about involuntary movement. In the case of involuntary movement there is $\mathrm{SO}$ for the movement but no SA. The neuroscience suggests that awareness of my involuntary movement is generated in reafferent sensory-feedback (visual and proprioceptive/kinaesthetic information that tells me that I'm moving). In the case of involuntary movement there are no initial motor commands (no efferent signals). Thus, it seems possible that in both involuntary and voluntary movement SO is generated by sensory feedback, and that in the case of voluntary movement SA is generated by efferent signals. Tsakiris and Haggard (2005; Tsakiris 2005) review empirical evidence that supports this division of labor. As they put it: 
[...] the sense of agency involves a strong efferent component, because actions are centrally generated. The sense of ownership involves a strong afferent component, because the content of body awareness originates mostly by the plurality of multisensory peripheral signals. We do not normally experience the efferent and afferent components separately. Instead, we have a general awareness of our body that involves both components. (Tsakiris and Haggard 2005, 387).

On this view SA is conceived as generated in motor-control related brain processes. But this may not be the whole story, as Haggard himself points out, since "actions seem to aim towards a goal, as if pulled teleologically from the intention through to the intended effect" $(2005,292)$. SA, in addition to a being sense of embodied movement, involves a sense of controlling events in the external world. Haggard accordingly distinguishes between "urge" and "effect" - the former associated with an experience generated in motor control processes, the latter associated with perceptual monitoring of what one actually accomplishes by the action. Both of these aspects, the intentional aspect (what gets accomplished, or fails to get accomplished, by the action) and the motor (or efferent) aspect (the sense that I am causing or controlling my bodily movement) enter into SA It seems clear that there is a confirmatory consistency between the neuroscience and the phenomenology. That is, phenomenologically one can make the same distinctions between SA taken as a sense of bodily control, and SA taken as a sense of controlling what one accomplishes in the world (Gallagher 2007).

In an fMRI experiment conducted by Farrer and Frith (2002), and designed to find the neural correlates of SA, subjects are asked to manipulate a joystick to drive a colored circle moving on a screen to specific locations on the screen. In some instances the subject causes this movement and in others the experimenter or computer does. The subject is asked to discriminate self-agency (when they feel they are in charge of the movement) and other-agency (when they feel the other person is in charge of the movement). Farrer and Frith citing the distinction between SA and SO, associate SA with the intentional aspect of action, i.e., whether I am having some kind of effect with respect to the goal or intentional task (or what happens on the screen). Accordingly, they claim that SO ("my hand is moving the joystick") remains constant while SA (based on the intentional aspect) changes. When subjects feel that they are not controlling the events on the screen, there is activation in the right inferior parietal cortex and supposedly no SA for the intentional aspect of the action. When the subject does have SA for the action on the screen, the anterior insula is activated bilaterally.

Although Farrer and Frith clearly think of SA as something tied to the intentional aspect of action and not to mere bodily movement or motor control, when it comes to explaining why the anterior insula should be involved in generating SA, they frame the explanation in terms of motor control.

Why should the parietal lobe have a special role in attributing actions to others while the anterior insula is concerned with attributing actions to the self? The sense of agency (i.e., being aware of causing an action) occurs in the context of a body moving in time and space. ... There is evidence that both the inferior parietal lobe and the anterior insula are representations of the body .... the anterior insula, in interaction with limbic structures, is also involved in the 
representation of body schema .... $(2002,601)$.

In all of these experiments the phenomenological distinctions are put to good use. Indeed, closer attention to the phenomenology of agency could help to clarify the distinction between the intentional aspect and the motor (efferent) aspect of agency, a distinction that can easily get lost in the neurological explanation. Phenomenologists can also suggest that there is more to SA than the pre-reflective elements delineated here. In actions that involve reflective deliberation or retrospective evaluation, these more reflective aspects of action, which may also bring into play social norms and forces that are not reducible to processes confined to individual brains, may enter into the experience of agency (Gallagher 2010). In this regard, phenomenology tends to support a nonreductionist approach to the naturalistic study of human agency.

The sense of ownership is also something that can be studied by experimental science. In the rubber hand illusion, you sit at a table with your left arm and hand placed under a cover (Botvinick and Cohen 1998). A rubber arm-hand is placed on the table in front of you, canonically positioned near your left hand. Your left hand undergoes passive tactile stimulation (e.g., a brushing of the fingers), and simultaneously you see the similar stimulation being made on the rubber hand. You almost immediately start to feel as if the rubber hand is your own, and you feel the stimulation as being in the rubber hand. SO, specifically your sense of body ownership, extends into the rubber hand.

In the rubber hand illusion experiment, the subject is not allowed to move his real hand, and this controls for SA. The focus is on SO. But what happens if we introduce movement? Tsakiris and Haggard (2005) demonstrated that during the rubber hand illusion there is a "proprioceptive drift" toward the rubber hand. That is, the passively stimulated finger (of one's real hand) was judged to be significantly closer to the location of the rubber hand than it really was. But this effect was localized only for the stimulated finger and not for the whole hand. Tsakiris and Haggard then hypothesized that a more holistic body (motor) schema, engaged when in action, and thereby involving SA, would contribute to a more coherent or holistic sense of embodiment. In a further experiment, subjects viewed video of their hands under two conditions: when the subject moves his own index finger, and when the subject's index finger is moved by the experimenter. In the first case of self-generated movement there is SA; in the second, passive movement, no SA. Tsakiris and Haggard show that while the proprioceptive drift in the passive movement is just for the one finger, the drift is for the whole hand in self-generated movement. They conclude that, "The active body is experienced as more coherent and unified than the passive body" (2005b; see Tsakiris, Schütz-Bosbach, and Gallagher 2007). Agency and the corresponding efferent signals involved modulate afferent feedback, and more generally bodily awareness, and thereby modulate the SO for one's actions. In the case of action, SO is integrated into the more holistic body-schematic processes of motor control, confirming suggests made from a phenomenological perspective about how we experience bodily action (Gallagher 2005).

\section{Pathologies}

The same distinction between SO and SA is useful in trying to make sense of a variety of pathologies. Here I'll focus on schizophrenic symptoms of delusions of control and thought insertion. There are, however, clear applications of the concepts of SO and SA to 
various disorders, such as Anarchic Hand Syndrome and Somatoparaphrenia (see, e.g., Gallagher and Væver 2004).

A schizophrenic patient may suffer from delusions of control, where he complains that someone else is controlling his bodily movement, or thought insertion, where he might claim that he is not the one who is thinking a particular thought, when in fact he is the one who is thinking the thought. Consider the following example of a schizophrenic's report: 'Thoughts are put into my mind like "Kill God". It's just like my mind working, but it isn't. They come from this chap, Chris. They're his thoughts' (from Frith 1992, p. 66). Frith offers an explanation of delusions of control and thought insertion in terms of a neurocognitive model in which normal self-monitoring breaks down. Frith (1992) appeals to the notions of efference copy and comparator mechanisms involved in motor control (Sperry 1950; Holst and Mittelstaedt 1950). Normally, a comparator mechanism operates as part of a non-conscious pre-motor or 'forward model' that compares efference copy of motor commands with motor intentions and allows for rapid, automatic error corrections (Wolpert et al. 2000; Frith et al. 2000). Putting this in terms of SA and $\mathrm{SO}$, the proposal is that the forward comparator process, based on efference copy, normally anticipates the sensory feedback from movement and generates SA, while the sensory-feedback processes themselves generate SO. If the forward model fails, or efference copy is not properly generated, sensory feedback may still produce SO ('I am moving') but SA will be compromised ('I am not causing the movement'), even if the actual movement matches the intended movement.

In the case of practiced voluntary action, SA and SO are indistinguishable; we noted, however, that they come apart in the case of involuntary action. In the case of delusions of control where the schizophrenic patient claims that he is not the agent of a particular action, SA is not present, but SO is still present, similar to the case of involuntary action. Indeed this is necessarily so for the patient's report to make sense: " $m y$ body has engaged in an action; my body has been moved" - this is his complaint, that he is the one being moved, or being made to act, and that the action is not something he intended. SO is still intact for his body and for his movement, even as the sense of self-agency is not. This is precisely why he feels that this movement or action is his concern rather than someone else's; it's not happening to someone else, it's happening to him.

It turns out that schizophrenic patients who suffer from delusions of control do have problems with the forward, pre-action monitoring of movement, but not with motor control based on a comparison of intended movement and sensory feedback (Frith and Done 1988; Malenka et al. 1982). While motor control based on sensory feedback is thought to involve the cerebellum (Frith et al. 2000), problems with forward monitoring are consistent with studies of schizophrenia showing abnormal pre-movement brain potentials associated with supplementary motor, premotor and prefrontal cortexes (Singh et al. 1992). On this account, problems in precisely these brain areas may therefore result in the lack of SA, characteristic of these kinds of schizophrenic experiences (Hohwy 2004; Gold and Hohwy 2000; Mundale and Gallagher 2008).

Turning to the problem of thought insertion, Frith (1992) considers thinking to be a form of action, and attempts to apply the same motor control model in this realm. If this solution works to explain delusions of control, however, it is not clear that it can also explain thought insertion. Indeed, phenomenologists are in a good position to argue that 
this solution does not work for thought insertion. A number of phenomenological issues become obvious when one tries to apply the motor control model to thinking. First, while it is possible to talk about an intention to act in a certain way, it is problematic to talk about an intention to think, since such an intention would be itself a thinking, and an infinite regress threatens.

Second, it is not clear what role something like efference copy or a comparator would play in conscious thinking. In the case of visuomotor control, efference copy serves a pragmatic, executive function - it informs the visual and vestibular systems that the organism, rather than the world, is moving. Its purpose is to instruct the motor or sensory system to make important adjustments. Is there anything like this happening in the thinking process? One might think that efference copy functions to keep thoughts on track, checking "that the thoughts you actually execute form coherent trains of thought" (Campbell 1999, 616). This proposal attributes a semantic function to a subpersonal, nonsemantic mechanism when, simply put, we are already consciously aware of our thoughts and can keep track of them, and keep them on track, at a conscious level.

Third, there are a number of aspects of the experience of thought insertion that Frith's comparator model simply does not explain. Most obviously, and in a similar way to the proposed solution to delusions of control, it might be able to explain the lack of SA, but it fails to explain why the schizophrenic who experiences thought insertion attributes the thought to someone else. Let me conclude, however, by mentioning one other problem. If there is a comparator mechanism for thought, and it breaks down or is put out of operation, why do not all thoughts seem alien to the schizophrenic? When a particular thought seems inserted, there are other aspects of conscious experience that do not seem inserted. Either simultaneously with, or immediately after the thought that seems inserted, there is the feeling that it is inserted. But this feeling does not itself feel inserted. That is, the subject, in recognizing a thought as inserted, does not claim that his recognition of this fact is also inserted. He is seemingly speaking in his own voice when he complains about the inserted thought. This is not just a phenomenological fact, it's a logical necessity. The subject's complaint that various thoughts are inserted depends on a necessary contrast between thoughts that seem inserted and those that do not seem inserted - and at a minimum, the thoughts that constitute the subject's complaint cannot seem inserted.

Just as the phenomenological distinction between SA and SO is able to clarify certain aspects of the schizophrenic's experience in cases of delusion of control and thought insertion, so also certain phenomenological considerations suggest that the same comparator model that might help to explain the breakdown of SA in delusions of control cannot provide an explanation of the breakdown of SA in thought insertion. These phenomenological interventions, accordingly, can contribute important insights that need to be taken into account in any neurocognitive account of these symptoms.

\section{Intersubjectivity}

One other area of concern where phenomenology can make important contributions pertains to questions about intersubjectivity. There is a long history of discussion within phenomenology about intersubjectivity, but up until approximately ten years ago such phenomenological considerations were not brought to bear on the ongoing debate within philosophy of mind, psychology, and cognitive science concerning social cognition or 
theory of mind (ToM). A number of phenomenologists have now developed a critique of the standard approaches, "theory theory" (TT) and simulation theory (ST), and have put forward alternative theories (Gallagher 2001; 2005; 2008; Gallagher and Hutto 2008; Ratcliffe 2006; Thompson 2001; Zahavi 2001).

The critique of TT and ST focuses on several claims made in these approaches: (1) that our normal everyday stance towards the other is a third-person observational one in which we attempt to explain and predict the other person's behavior; (2) that such explanation and prediction depends on inferring or simulating ("mindreading") the other's mental states which are generally hidden from view; (3) that our ability to mindread is the result of some mechanism found in the individual mind or brain (a ToM mechanism or mirror neurons); and (4) that these mindreading processes are primary and pervasive, characterizing the majority of our everyday encounters. For those theories that make the mindreading processes (whether theoretical inferences or simulation routines) conscious or introspective (e.g., Goldman 1995; 2006), phenomenology points out that there is simply no evidence of such processes in our everyday experiences, and that such processes are not primary and pervasive. Rather than third-person observation, our relations with others are better characterized in terms of second-person interaction where most of what we need for a pragmatic understanding of the other person are not hidden mental states, but embodied expressions that we can easily perceive on their faces, in their postures, movements and gestures - none of which float around in thin air but are situated in social and pragmatic contexts. On the phenomenological view, interaction, rather than observation, constitutes our primary way of being with others, and social cognition is not reducible to some mechanism or set of processes found within the individual, since it involves the individual in dynamic processes with others and in an environment that is already social.

One important issue that continues to be a point of dispute between the standard approaches and phenomenological approaches concerns the relevance of phenomenology for understanding subpersonal processes that are, of course, non-conscious (Spaulding 2010). Can phenomenology tell us anything about mirror neuron activation, for example? In this regard some defenders of the standard TT and ST approaches dismiss phenomenology as irrelevant. The role of phenomenology is not to ascertain the nature of specific sub-personal processes, of course. It is possible, however, to look to phenomenology for part of the evidence about what might be going on at the level of subpersonal processes. Since phenomenology can help to specify the explanandum on the personal level - e.g., whether we are attempting to explain something that involves conscious reflective processes, of an inferential or a simulative nature perhaps, or more pre-reflective bodily perceptual processes, it can provide clues about what might be happening at the subpersonal level, and perhaps contribute to our understanding of why correlational neuronal activations in frontal areas versus more primary perceptual-motor systems make sense. This corresponds, moreover, to a current scientific view of things. Thus, for example, Gallese (2001) claims that a phenomenology of empathy correlates with sub-personal simulation on a functionalist level, and with mirror neuron activation on a neurological level. That claim may be correct, or not. But even on a more methodological level pertaining to how the relevant experiments are done, if subjects are not in a specific personal-level situation (e.g., attending to the other's actions) there is no expectation that MNs will fire, or that low-level simulations will happen. Neuroscientists 
frequently appeal to personal level practices and phenomenological experiences in setting up their experiments, and in many cases the only way to define the explanadum is in terms of phenomenology. Without phenomenology it is not clear that an analysis of mechanical subpersonal processes plus mindless behavior can add up to anything like a full account of human social cognition.

\section{Conclusion: Collaboration and mutual enlightenment}

There are clearly multiple ways in which one can naturalize phenomenology, in the sense of integrating phenomenological data, methods, and insights into natural scientific experiments in cognitive science, including psychology and neuroscience, without engaging in naturalistic reductionism. I have not provided an exhaustive list of all possible ways. Practically speaking one of the most straight-forward and productive ways of providing opportunity for this kind of integration is for phenomenologists to work together with psychologists and neuroscientists. Just this kind of engagement may be what Dan Zahavi has in mind when he writes:

To naturalize phenomenology might simply be a question of letting phenomenology engage in a fruitful exchange and collaboration with empirical science. Phenomenology does study phenomena that are part of nature and therefore also open to empirical investigation, and insofar as phenomenology concerns itself with such phenomena it should be informed by the best available scientific knowledge. (Zahavi 2010,8)

It remains the case that phenomenology is an attempt to do justice to first- and second-person experiences, to explicate such experiences in terms of their meaning. As such, phenomenology does not directly address the questions of subpersonal mechanisms or causal factors. And yet phenomenology can offer some insight to the studies of consciousness and cognition, at the very least by providing personal-level descriptions of the explicandum for those studies. Furthermore, it is a matter of historical fact that phenomenology (in the works of Gurwitsch and Merleau-Ponty, for example) has always learned from disciplines such as psychopathology, neuropathology, developmental psychology, cognitive psychology, and neuroscience. The influence goes both ways, in a process of mutual enlightenment (Gallagher 1997).

Mutual enlightenment is a relatively mild way to put it, however. A more radical proposal would be to pursue what Merleau-Ponty called the "truth of naturalism" and the idea that "it would be necessary to define transcendental philosophy anew in such a way as to integrate with it the very phenomenon of the real" (SB). The "truth" of naturalism is not the naturalism Husserl cautioned against, but a redefined non-reductionist naturalism that correlates with a redefined phenomenology. 


\section{References}

Botvinick, M. and Cohen, J. 1998. Rubber hands 'feel' touch that eyes see. Nature 391: 756

Campbell, J. 1999. Schizophrenia, the space of reasons and thinking as a motor process. The Monist 82 (4): 609-625.

Damasio, A.R. 1994. Descartes' Error: Emotion, Reason, and the Human Brain. New York: Putnam Publishing.

De Jaegher, H., Di Paolo, E. and Gallagher, S. 2010. Does social interaction constitute social cognition? Trends in Cognitive Sciences 14 (10): 441-447.

De Preester, H. 2002. Naturalizing Husserlian phenomenology: An introduction. Psychoanalytische Perspectieven 20, 4: 633-647

Dreske, F. 1997. Naturalizing the Mind. Cambridge, MA: MIT Press.

Dreyfus, H. 1973. What Computers Can't Do, New York: Cambridge, MA: MIT Press

Edelman, S. 2002. Constraints on the nature of the neural representation of the visual world. Trends in Cognitive Sciences 6: 125-31

Farrer, C., Franck, N. Georgieff, N. Frith, C.D. Decety, J. and Jeannerod, M. 2003. Modulating the experience of agency: a positron emission tomography study. NeuroImage 18: 324-333

Farrer, C. and Frith, C.D. 2002. Experiencing oneself vs. another person as being the cause of an action: the neural correlates of the experience of agency. NeuroImage 15: 596-603.

Frith, C. D. 1992. The Cognitive Neuropsychology of Schizophrenia. Hillsdale, NJ: Lawrence Erlbaum Associates.

Frith, C. D., Blakemore, S., \& Wolpert, D. 2000. Abnormalities in the awareness and control of action. Philosophical Transactions of the Royal Society of London 355: 1771-1788.

Frith, C.D. and Done, D.J. 1988. Towards a neuropsychology of schizophrenia. British Journal of Psychiatry 153: 437-43

Gallagher, S. 2010. Multiple aspects of agency. New Ideas in Psychology. (http://dx.doi.org/10.1016/j.newideapsych.2010.03.003). Online publication April 2010.

Gallagher, S. 2008. Inference or interaction: Social cognition without precursors. Philosophical Explorations, 11 (3), 163-73.

Gallagher, S. 2007. The natural philosophy of agency. Philosophy Compass. 2 (2): 347357

(http://www.blackwell-synergy.com/doi/full/10.1111/j.17479991.2007.00067.x)

Gallagher, S. 2005. How the Body Shapes the Mind. Oxford: Oxford University Press.

Gallagher, S. 2001. The practice of mind: Theory, simulation or primary interaction? Journal of Consciousness Studies, 8(5-7), 83-108.

Gallagher, S. 2003. Phenomenology and experimental design. Journal of Consciousness Studies 10 (9-10): 85-99

Gallagher, S. 2001. The practice of mind: Theory, simulation, or interaction? Journal of Consciousness Studies, 8 (5-7): 83-107

Gallagher, S. 2000. Philosophical conceptions of the self: implications for cognitive science. Trends in Cognitive Science 4 (1): 14-21. 
Gallagher, S. 1997. Mutual enlightenment: Recent phenomenology in cognitive science. Journal of Consciousness Studies 4 (3): 195-214.

Gallagher, S. and Brøsted Sørensen, J. 2006. Experimenting with phenomenology. Consciousness and Cognition 15 (1): 119-134

Gallagher, S. and Hutto, D. 2008. Understanding others through primary interaction and narrative practice. In: J. Zlatev, T. Racine, C. Sinha and E. Itkonen (eds). The Shared Mind: Perspectives on Intersubjectivity (17-38). Amsterdam: John Benjamins.

Gallagher, S. and Varela, F. 2003. Redrawing the map and resetting the time: Phenomenology and the cognitive sciences. Canadian Journal of Philosophy, (Supplementary) 29: 93-132.

Gallagher, S. and Mette Væver. 2004. Disorders of embodiment. In J. Radden (ed.), The Philosophy of Psychiatry: A Companion (pp. 118-32). Oxford: Oxford University Press.

Gallese, V. 2001: The 'shared manifold' hypothesis: from mirror neurons to empathy. Journal of Consciousness Studies, 8, 33-50.

Gold, I. and Hohwy, J. 2000. Rationality and schizophrenic delusion. In M. Coltheart, and M. Davies (eds.), Pathologies of Belief (145-165). Blackwell, Oxford.

Goldman, A. I., 1995: Desire, intention and the simulation theory. In B. F. Malle, L. J. Moses, and D. A. Baldwin (eds.), Intentions and Intentionality: Foundations of Social Cognition (pp. 207-224). Cambridge, MA: MIT Press.

Goldman, A. I. 2006: Simulating Minds: The Philosophy, Psychology, and Neuroscience of Mindreading. New York: Oxford University Press.

Gurwitsch, A. 2009. The Collected Works of Aron Gurwitsch (1901-1973). Vol. I Constitutive Phenomenology in Historical Perspective Trans. \& Ed. J. GarcíaGómez. Dordrecht: Springer.

Haggard, P. 2005. Conscious intention and motor cognition. Trends in Cognitive Sciences 9 (6): 290-95.

Haggard, P., and Libet, B. 2000. Conscious intention and brain activity. Journal of Consciousness Studies 8 (11): 47-63

Hohwy, J. 2004. Top-down and bottom-up in delusion formation. Philosophy, Psychiatry and Psychology 11: 65-70.

Holst E von, and Mittelstaedt H. 1950. Das Reafferenzprinzip (Wechselwirkungen zwischen Zentralnervensystem und Peripherie). Naturwisenschaften 37: 464-76.

Husserl, E. 1965. Phenomenology and the Crisis of Philosophy [original: 1911]. Trans. Q. Lauer. New York: Harper.

Husserl, E. 1970. Cartesian Meditations. Trans. D. Cairns. The Hague: Martinus Nijhoff.

Husserl, E. 1976. Ideen zu einer reinen Phänomenologie und phänomenologischen Philosophie I, Husserliana III/1-2. The Hague: Martinus Nijhoff; Ideas Pertaining to a Pure Phenomenology and to a Phenomenological Philosophy. First Book. General Introduction to a Pure Phenomenology. Trans. F. Kersten. The Hague: Martinus Nijhoff, 1982.

Husserl, E. 1977. Phenomenological Psychology. Trans. J. Scanlon. Hague: Martinus Nijhoff.

Husserl, E. 2001. Logical Investigations, 3 vols., trans. J.N. Findlay. London: Routledge. 
Husserl, Edmund 2005. Phantasy, Image Consciousness, and Memory (1898-1925).

Trans. J. B. Brough. Collected Works, Volume XI. Dordrecht: Springer.

James, W. 1890. Principles of Psychology. New York: Dover, 1950.

Jeannerod, M. 1997. The Cognitive Neuroscience of Action. Oxford: Blackwell Publishers.

Lawlor, L. 2009. Becoming and Auto-Affection (Part II): Who are we? Invited Lecture, ICNAP, 2009. Published at http://www.icnap.org/meetings.htm (accessed 15 January 2011)

Le Van Quyen, M. 2003. Disentangling the dynamic core: A research program for neurodynamics at the large-scale. Biological Research 36: 67-88.

Le Van Quyen, M., \& Petitmengin, C. 2002. Neuronal dynamics and conscious experience: An example of reciprocal causation before epileptic seizures. Phenomenology and the Cognitive Sciences 1, 169-180.

Libet, B. 1985. Unconscious cerebral initiative and the role of conscious will in voluntary action. Behavioral and Brain Sciences, 8: 529-66.

Libet, B., Gleason, C.A.,Wright, E.W. \& Pearl, D.K. 1983. Time of conscious intention to act in relation to onset of cerebral activity (readiness potential): The unconscious initiation of a freely voluntary act. Brain 106: 623-42

Lutz, A. (2002), Toward a neurophenomenology as an account of generative passages: A first empirical case study. Phenomenology and the Cognitive Sciences 1: 133-67.

Lutz, A., Lachaux, J.-P., Martinerie, J., and Varela, F. J. (2002), Guiding the study of brain dynamics using first-person data: Synchrony patterns correlate with on-going conscious states during a simple visual task. Proceedings of the National Academy of Science USA: 99, 1586-1591.

Lutz, A. and Thompson, E. 2003. Neurophenomenology: Integrating lived experience into cognitive neuroscience. Journal of Consciousness Studies 10: 31-52.

Malenka R.C., Angel R.W., Hampton B. and Berger P.A. 1982. Impaired central error correcting behaviour in schizophrenia. Arch Gen Psychiat 39: 101-107.

Marbach, E. 1993. Mental Representation and Consciousness: Towards a Phenomenological Theory of Representation and Reference. Dordrecht: Kluwer Academic Publishers.

Marbach, E. 2010. Towards a formalism for expressing structures of consciousness. In S. Gallagher and D. Schmicking (eds.), Handbook of Phenomenology and Cognitive Science. Dordrecht: Springer.

Merleau-Ponty, M. 2010. Child Psychology and Pedagogy: The Sorbonne Lectures 19491952. Trans. T. Welsh. Evanston: Northewestern University Press.

Merleau-Ponty, M. 1962. Phenomenology of Perception. Trans. C. Smith. London: Routledge and Kegan Paul.

Mundale, J. and Gallagher, S. 2009. Delusional experience. In J. Bickle (ed). Oxford Handbook of Philosophy and Neuroscience (513-521). Oxford: Oxford University Press.

Noë, A. 2004. Action in Perception. Cambridge, MA: MIT Press.

Petitot, J. 2008. Neurogéométrie de la vision: modèles mathématiques et physiques des architectures fonctionnelles. Montreal: Presses internationales Polytechnique.

Petitot, J. 1999. Morphological eidetics for a phenomenology of perception. In J.

Petitot, F.J. Varela, B. Pachoud, and J.-M. Roy (eds.), Naturalizing Phenomenology: 
Issues in Contemporary Phenomenology and Cognitive Science, (330-371). Stanford, CA: Stanford University Press.

Pöppel, E. 1994. Temporal mechanisms in perception. International Review of Neurobiology 37: 185-202.

Price, D., Barrell, J., and Rainville, P. 2002. Integrating experiential-phenomenological methods and neuroscience to study neural mechanisms of pain and consciousness. Consciousness and Cognition 11: 593-608.

Ratcliffe, M. 2007. Rethinking Commonsense Psychology: A Critique of Folk Psychology, Theory of Mind and Simulation. Basingstoke: Palgrave Macmillan.

Roy, J.-M., Petitot, J., Pachoud, B. \& Varela, F.J. 1999. Beyond the gap: An introduction to naturalizing phenomenology. In J. Petitot, F. J. Varela, B. Pachoud \& J.-M. Roy (Eds.), Naturalizing Phenomenology: Issues in Contemporary Phenomenology and Cognitive Science (1-80). Stanford, CA: Stanford University Press.

Sartre, J-P. 2004. The Imaginary: A Phenomenological Psychology of the Imagination. Trans. J. Webber. London: Routledge.

Sartre, J-P. 1956. Being and Nothingness. New York: Philosophical Library.

Schacter, D.L., Reiman, E., Curran, T., Yun, L.S., Bandy, D., McDermott, K.B., \& Roediger, H.L. 1996. Neuroanatomical Correlates of Veridical and Illusory Recognition Memory: Evidence from Positron Emission Tomography. Neuron 17(2): 267-74.

Singh JR, Knight T, Rosenlicht N, Kotun JM, Beckley DJ, Woods DL. 1992. Abnormal premovement brain potentials in schizophrenia. Schizophrenia Research 8: 31-41.

Skewes, J. C. 2011. Agency: A philosophical context in psychological science. Ph.D. Dissertation, Faculty of Humanities, Aarhus University.

Sperry R.W. 1950. Neural basis of the spontaneous optokinetic response produced by visual inversion. J Comp Phys Psychology 43: 482-89.

Thompson, E. 2007. Mind in Life: Biology, Phenomenology, and the Sciences of Mind. Cambridge, MA: Harvard University Press.

Thompson, E. 2001. Between Ourselves: Second Person Issues in the Study of Consciousness. Exeter: Imprint Academic.

Thompson, E., Lutz, A. and Cosmelli, D. 2005. Neurophenomenology: An Introduction for Neurophilosophers. In: A. Brook and K. Akins (eds.), Cognition and the Brain: The Philosophy and Neuroscience Movement. New York and Cambridge: Cambridge University Press.

Tsakiris, M. 2005. On agency and body-ownership. Paper presented at Expérience Subjective Pré-Réflexive \& Action (ESPRA) Conference, CREA, Paris. December 2005.

Tsakiris, M. and Haggard, P. 2005. Experimenting with the acting self. Cognitive Neuropsychology 22 (3/4): 387-407.

Tsakiris M., Hesse M.D., Boy C., Haggard P. and Fink G.R. 2007. Neural signatures of body ownership: A sensory network for bodily self-consciousness. Cerebral Cortex. 17, 2235-44.

Tsakiris, M., Schütz-Bosbach, S. and Gallagher, S. 2007. On agency and bodyownership: Phenomenological and neurocognitive reflections. Consciousness and Cognition 16 (3): 645-660 
Tsakiris, M., Prabhu, G. \& Haggard, P. 2006. Having a body versus moving your body: How agency structures body-ownership. Consciousness and Cognition 15(2): 423432.

Varela, F. J. 1996. Neurophenomenology: A methodological remedy for the hard problem. Journal of Consciousness Studies, 3 (4): 330-49.

Varela, F.J. 1999. The specious present: A neurophenomenology of time consciousness. In J. Petitot, F.J. Varela, B. Pachoud, and J.-M. Roy, eds., Naturalizing Phenomenology: Issues in Contemporary Phenomenology and Cognitive Science (266-314). Stanford, CA: Stanford University Press.

Varela, F., Thompson, E., and Rosch, E. 1991: The Embodied Mind. Cambridge, MA: MIT Press.

Wolpert, D. M. \& Ghahramani, Z. 2000. Computational principles of movement neuroscience. Nature Neuroscience Supplement, 3: 1212-1217.

Zahavi. D. 2010. Phenomenology and the problem of naturalization. In S. Gallagher and D. Schmicking (eds.), Handbook of Phenomenology and Cognitive Science. Dordrecht: Springer.

Zahavi, D. 2004. Phenomenology and the project of naturalization. Phenomenology and the Cognitive Sciences 3(4), 331-347.

Zahavi, D. 2001. Beyond empathy: Phenomenological approaches to intersubjectivity. Journal of Consciousness Studies 8 (5-7): 151-167. 